\title{
Hepatic adrenal adenoma-rare tumor on right lobe of liver: a case report and literature review
}

\author{
Haibo Yu* ${ }^{*}$ and Yadong He
}

\begin{abstract}
Background: Hepatic adrenal ectopia is a common clinical diagnosis, whereas adrenal tumors developed from hepatic adrenal ectopia are rare. Hepatic adrenal tumors are easily misdiagnosed as hepatic carcinoma and frequently treated by unnecessary operations.

Case presentation: A 50-year-old female patient was hospitalized due to B-ultrasonic detection of "right focal liver lesions." After hospitalization, enhanced CT examination was performed. A $2.2 \mathrm{~cm} \times 1.8 \mathrm{~cm}$ tumor was found in the seventh section of the right liver, as indicated by obvious enhancement of the arterial phase and low density during the portal vein and delay stages. Enhanced MRI examination detected a $2.0 \mathrm{~cm} \times 1.8 \mathrm{~cm}$ tumor on the right liver, which was considered a "primary hepatic carcinoma". The patient was treated by open hepatectomy and recovered well after the operation. The postoperative pathological diagnosis was hepatic adrenal adenoma. No relapse was observed through the 1-year follow-up visit.

Conclusions: According to imaging manifestations, pathological immunohistochemical treatment, alpha fetoprotein (AFP) and clinical features, hepatic adrenal tumors should be considered in the diagnosis of hepatic carcinoma to prevent misdiagnosis. Hepatic adrenal tumors should be ruled out during the diagnosis to avoid unnecessary operation.
\end{abstract}

Keywords: Hepatic adrenal adenoma, Hepatic carcinoma, Hepatic adrenal ectopia

\section{Background}

Heterotopic adrenal tissue is commonly diagnosed in the clinic. According to Vestfrid MA [1], heterotopic adrenal tissue is detected in $50 \%$ of newborns and children and in $1 \%$ of adults. Heterotopic adrenal tissue exists in many parts of the human body and is mostly common on retroperitoneal fats close to the adrenal gland. Ectopic adrenal tissue includes renal adrenal ectopia and hepatic adrenal ectopia. These ectopic adrenals, particularly hepatic adrenal ectopia, may occasionally cause hyperplasia

\footnotetext{
* Correspondence: zjuboby@zuaa.zju.edu.cn
Department of Hepatobiliary Surgery, Wenzhou Central Hospital, The Dingli

* Correspondence: zjuboby@zuaa.zju.edu.cn
Department of Hepatobiliary Surgery, Wenzhou Central Hospital, The Dingli Clinical Institute of Wenzhou Medical University, Wenzhou, Zhejiang, People's Republic of China 325000
}

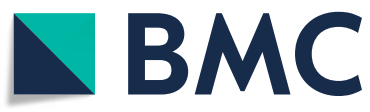

(C) The Author(s). 2020 Open Access This article is licensed under a Creative Commons Attribution 4.0 International License, which permits use, sharing, adaptation, distribution and reproduction in any medium or format, as long as you give appropriate credit to the original author(s) and the source, provide a link to the Creative Commons licence, and indicate if changes were made. The images or other third party material in this article are included in the article's Creative Commons licence, unless indicated otherwise in a credit line to the material. If material is not included in the article's Creative Commons licence and your intended use is not permitted by statutory regulation or exceeds the permitted use, you will need to obtain permission directly from the copyright holder. To view a copy of this licence, visit http://creativecommons.org/licenses/by/4.0/ The Creative Commons Public Domain Dedication waiver (http://creativecommons.org/publicdomain/zero/1.0/) applies to the data made available in this article, unless otherwise stated in a credit line to the data. cancer because of their similar imaging manifestations [2].

In 1935, Weller first reported hepatic adrenal ectopia [3]. However, the first case of hepatic adrenal ectopia was detected through the autopsy of a 27-year-old female who died from phthisis in 1885 . Weller believed that adrenal ectopia is caused by partial or complete integration of the adrenal glands with the kidney or liver. In 1968, Dolan detected five cases of adrenohepatic fusion (AHF) from 115 autopsies and categorized them as adrenohepatic adhesion (AHA) and AHF [4]. In 1976, Honoré LH reported AHA and AHF and analyzed their relevant mechanisms; the results showed that such tumors that develop from ectopic adrenals are rare and should be investigated by surgeons and pathologists to 
ensure systematic accumulation of many cases and reduce misdiagnosis [5]. In 1991, Honma systematically introduced AHF and defined it as the combination of liver tissues and (right) adrenal glands with tight mixing of their parenchyma cells. The pathological state of AHF differs from adrenohepatic adhesion. Honma detected 63 AHF cases from 636 autopsies, indicating that AHF was not rare [6].

This study reports a case of a patient with rare hepatic adrenal adenoma, which was misdiagnosed as liver cancer and treated by tumor excision.

\section{Case presentation}

A female patient was hospitalized for "B-ultrasonic detection of focal liver lesion for 1 month." The patient had neither history of hypertension, diabetes, hepatitis B, or hepatitis $\mathrm{C}$ nor symptoms of stomachache, abdominal distension, nausea, dizziness, or change in stool properties. The patient had no family history of genetic diseases or tumors and had not taken drugs for a long period.

The patient was diagnosed with "primary hepatic carcinoma" before hospitalization. Routine blood examination, biochemical tests, and analyses of alpha fetoprotein (AFP), carcinoembryonic antigen (CEA), cancer antigen 125 (CA125) and cancer antigen 19-9 (CA19-9), three systems of hepatitis B, hepatitis C antibody, HIV, RPR, and coagulation function were conducted. The results showed no obvious anomalies. According to B-ultrasound reexamination, a $2.1 \mathrm{~cm} \times 1.6 \mathrm{~cm}$ echo node was found on the right lobe of the liver, and an even internal echo and clear boundary was detected (Fig. 1). Enhanced CT of the abdomen showed an irregularly enhanced node at the seventh section of the arterial phase. The node contained edges enhanced in a circular manner and few fat dense particles. The enhancement was evident during the venous portal and delayed stages. The focus size was $2.2 \mathrm{~cm} \times 1.8 \mathrm{~cm}$, showing clear boundaries (Fig. 2). Enhanced magnetic resonance imaging (MRI) revealed an abnormal signal of the nodule $(20 \mathrm{~mm} \times 18 \mathrm{~mm}$ with clear boundary) at the S7 section of the liver. T1WI presented equisignals, and the antiphase was considerably lower than the in-phase. T2WI and T2WI + FS presented slightly higher signals, diffusion-weighted imaging (DWI) presented a high signal, and the apparent diffusion coefficient $(\mathrm{ADC})$ presented a slightly lower signal. These signals were considerably enhanced during enhanced arterial phase scanning but disappeared during the venous portal and delayed stages. All signals detected were located lower than the liver parenchyma (Fig. 3). These results led to the diagnosis of hepatocellular carcinoma, and hepatectomy was planned. Under general anesthesia, the patient underwent open hepatectomy. Resection was performed under the guidance of intraoperative ultrasonography. It took about $180 \mathrm{~min}$ and caused $50 \mathrm{ml}$ blood loss. The surgical specimen size was approximately $2.1 \mathrm{~cm} \times 2.0 \mathrm{~cm} \times 1.8 \mathrm{~cm}$ (Fig. 4). Hematoxylin/eosin (HE) staining was conducted in accordance with the pathological examination results. The tumor had clear boundaries, enveloped with a thin fibroid membrane, and was surrounded with some liver tissues. The tumor was composed of different proportions of bright and dark cells of acidophilic cytoplasm. These cells were distributed in cable or chests, accompanied by abundant blood vessels and sinusoidal structures (organ-like structures). The cell nuclei were round or oval and presented slight atypia. Aberrant cell nuclei were observed, and mitosis was rare (Fig. 5). Immunohistochemical examination showed the following results: inhibin- $\alpha(+)$ (Fig. 6.a), synaptophysin (+) (Fig. 6.b), melan-A (-), CK (-) (Fig. 6.c), cyclin D1 (-), chromogranin A (-), P53 (-), and hepatocytes (-) (Fig. 6.d). The final pathological diagnosis was adrenal cortical adenoma. The patient was discharged from the hospital after the operation. B-ultrasonication was performed 6 months after surgery and 1 year after surgery. The patient showed no relapse after 1 year of follow-up visits.

\section{Discussion and conclusions}

Although hepatic adrenal ectopia is a common pathological state, cases where it causes adrenal tumors are

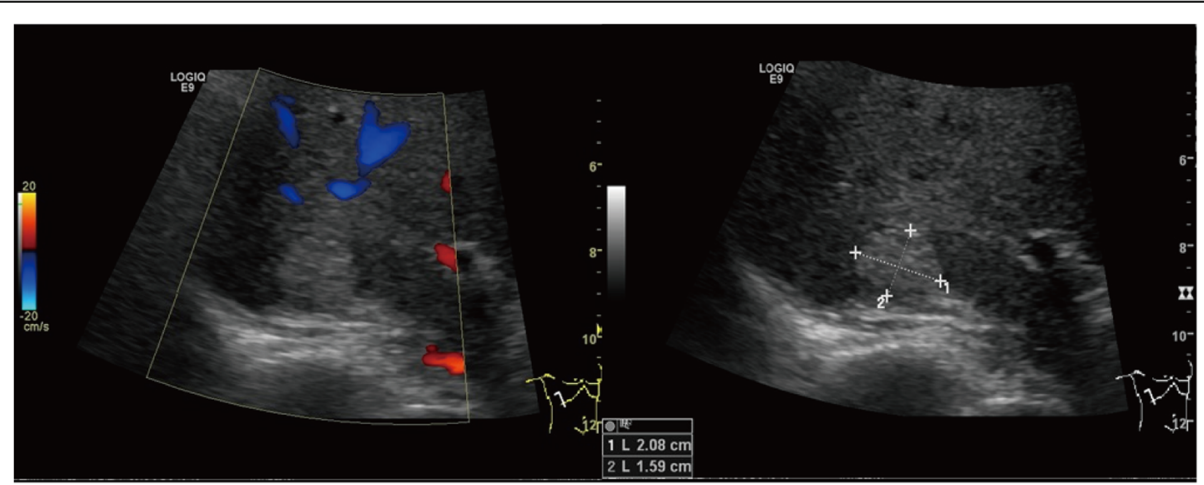

Fig. 1 B-ultrasound reexamination showing a $2.1 \mathrm{~cm} \times 1.6 \mathrm{~cm}$ echo node on the right lobe of the liver 


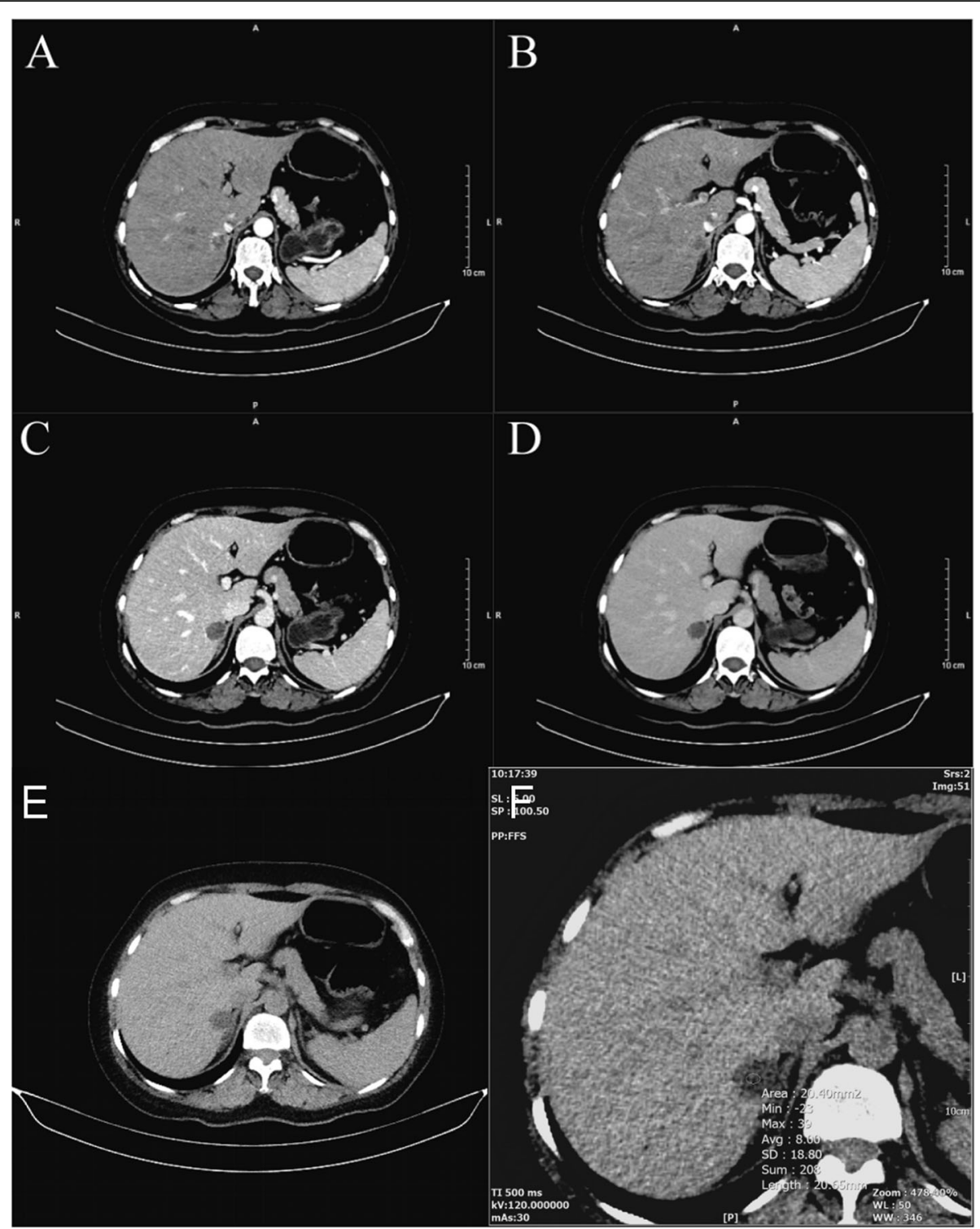

Fig. 2 Enhanced $C T$ of the abdomen showing an irregularly enhanced node at the seventh section of the arterial phase. The node contained edges enhanced in a circular manner and a few dense fat particles. The enhancement was evident during the venous portal and delayed stages. The focus size was $2.2 \mathrm{~cm} \times 1.8 \mathrm{~cm}$, showing clear boundaries. The average ordinary CT value of the tumor was $8 \mathrm{Hu}$

rare. To date, only ten cases of hepatic adrenal tumors have been reported in English (Table 1), and all these cases were from Asia. The clinical manifestations, CT examination, pathological results, and immunohistochemical results of these cases were analyzed. Among the ten patients, only one was diagnosed with functional adenoma, which was recognized as aldosteronoma [7]. The nine remaining patients did not develop functional tumors. Nine patients underwent excision for highly suspected liver cancer, and only one patient underwent radiofrequency ablation treatment because of refusal to undergo surgery. A clear diagnosis of hepatic adrenal tumor cannot be made according to the imaging data and clinical manifestations. Hepatic adrenal tumors are often diagnosed as liver cancer or metastatic liver tumors. Accurate diagnosis of hepatic adrenal tumors are vital to avoid unnecessary liver excision.

Hepatic adrenal adenoma has no unique clinical symptoms, except the presence of malignant or functional lesions. Patients are often diagnosed by imaging examination. However, no unique changes are detected in the imaging diagnosis of hepatic adrenal adenoma [13]. Adrenal tumors have rich lipid content and can be easily detected by $\mathrm{B}$ ultrasonic examination, MRI, and ordinary CT [14]. Hepatic adrenal tumors develop by fusion of adrenal liver tissues and might be misdiagnosed as metastatic or 


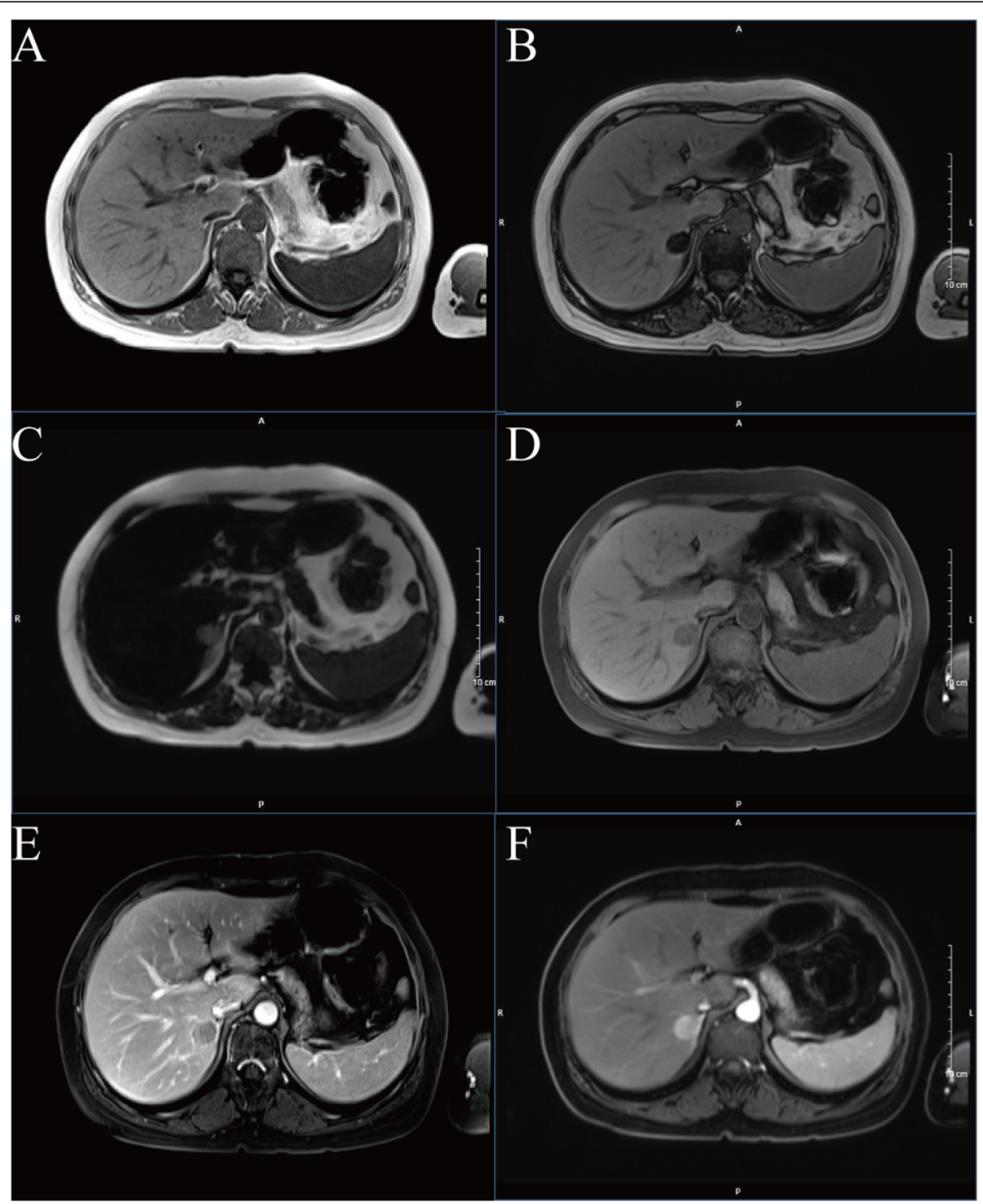

Fig. 3 Enhanced magnetic resonance imaging (MRI) uncovered an abnormal signal of the nodule $(20 \mathrm{~mm} \times 18 \mathrm{~mm}$ with clear boundary) at the S7 section of the liver. T1WI presented equisignals, and the antiphase was considerably lower than the in-phase. T2WI and T2WI + FS presented slightly higher signals, DWI presented a high signal, and the ADC presented a slightly lower signal. These signals were considerably enhanced during enhanced arterial phase scanning but disappeared during the venous portal and delayed stages. All signals detected were located lower than the liver parenchyma

malignant tumors. Park conducted an imaging analysis of hepatic adrenal adenoma and concluded that it might be diagnosed if the plain $\mathrm{CT}$ scan value of the lesion is less than or equal to $10 \mathrm{HU}$ and when the lesion is continuous with the right adrenal gland on multiplanar reconstruction images $[8,15]$. In our reported case, the average ordinary $\mathrm{CT}$ value of the tumor was $8 \mathrm{HU}$ (Fig. 2.F). Abdominal CT showed ambiguous boundaries between the right liver node and the lateral branch on the right adrenal gland (Fig. 2.E). Therefore, hepatic adrenal adenoma was highly suspected based on these imaging manifestations.
Kawasaki believed adrenocortical SPECT/CT should be taken into consideration to diagnose hepatic adrenal rest [16]. There was obvious uptake in the liver lesion and faint uptake in the adrenal glands. Similarly, based on similar pathological basis, we believe that using of adrenocortical SPECT/CT may be helpful for the diagnosis of hepatic adrenal adenoma. Despite the rapid development of imaging, core-needle biopsy still remains the gold standard for diagnosing liver diseases [17]. In our hospital, we often use ultrasound-guided 18-gauge core-needle biopsy. In this case, percutaneous liver core-needle biopsy could be a suitable diagnostic method before the surgery. 


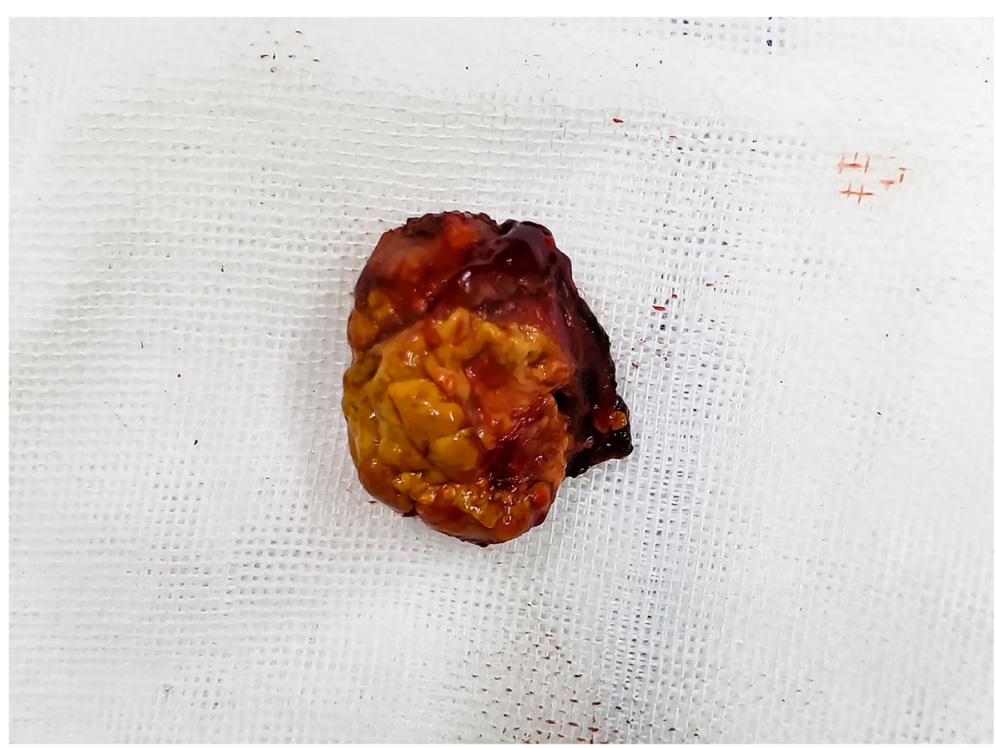

Fig. 4 The surgical specimen size was approximately $2.1 \mathrm{~cm} \times 2.0 \mathrm{~cm} \times 1.8 \mathrm{~cm}$

The final diagnosis of hepatic adrenal adenoma requires pathological examination. Hepatic adrenal adenoma can be successfully diagnosed in terms of its morphology and the existence of residual normal heterotopic adrenal cortical tissues. Immunohistochemical examination is conducive to distinguishing hepatocellular carcinoma from metastatic cancer. In adrenocortical adenoma, synaptophysin, inhibin- $\alpha$, and melan-A might be positive, and hepatocytes, which are generally related to liver cancer, are negative. In the present case, inhibin$\alpha(+)$, synaptophysin $(+)$, and hepatocytes $(-)$ were detected on pathological immunohistochemical examination. However, few relevant cases have been reported, and a unified diagnosis standard has not been established. In particular, collecting relevant clinical information by fine-needle aspiration biopsy is necessary upon suspicion of adrenal tumors. Attention should be paid to the patient's history of hypertension, chronic liver disease, and phymatosis. Examination results, such as AFP and CEA results, should be considered, and appropriate immunohistochemical staining should be applied for final accurate diagnosis.

According to this study, the possibility of hepatic adrenal adenoma should be considered for patients diagnosed with hepatic carcinoma by imaging examination. Diagnosis should be made by combining data on disease history, blood examination, imaging characteristics, and biopsy if necessary. The diagnosis of hepatic adrenal adenoma should be ruled out to avoid unnecessary operation. Analysis of a large number of patients is required

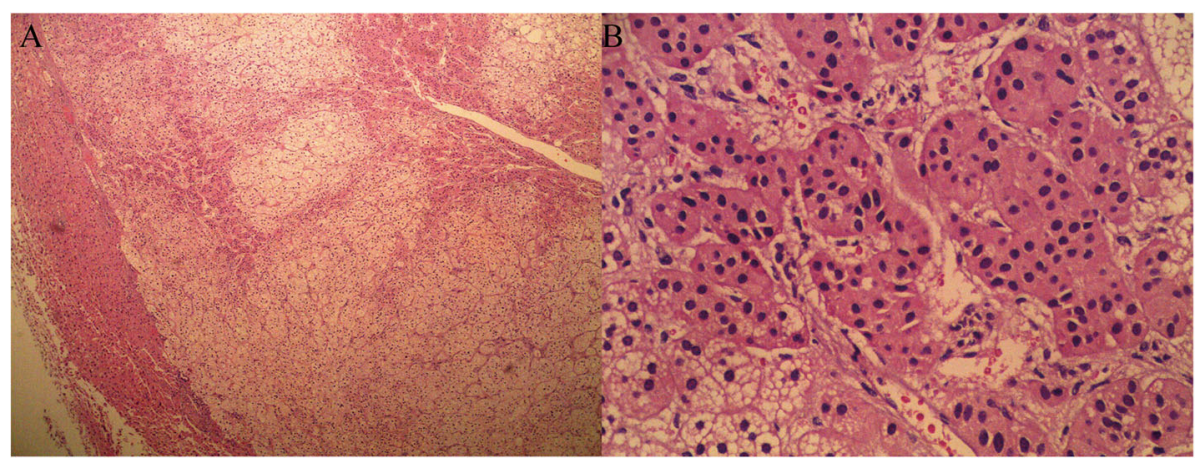

Fig. 5 The tumor had clear boundaries, enveloped with a thin fibroid membrane and surrounded with some liver tissues. The tumor was composed of different proportions of bright and dark cells of acidophilic cytoplasm. These cells were distributed in cable or chests, accompanied by abundant blood vessels and sinusoidal structures (organ-like structures). The cell nucleus was round or oval and presented slight atypia. Aberrant cell nuclei were observed, and mitosis was rare (A. HE $\times 50$; B, HEX 400) 


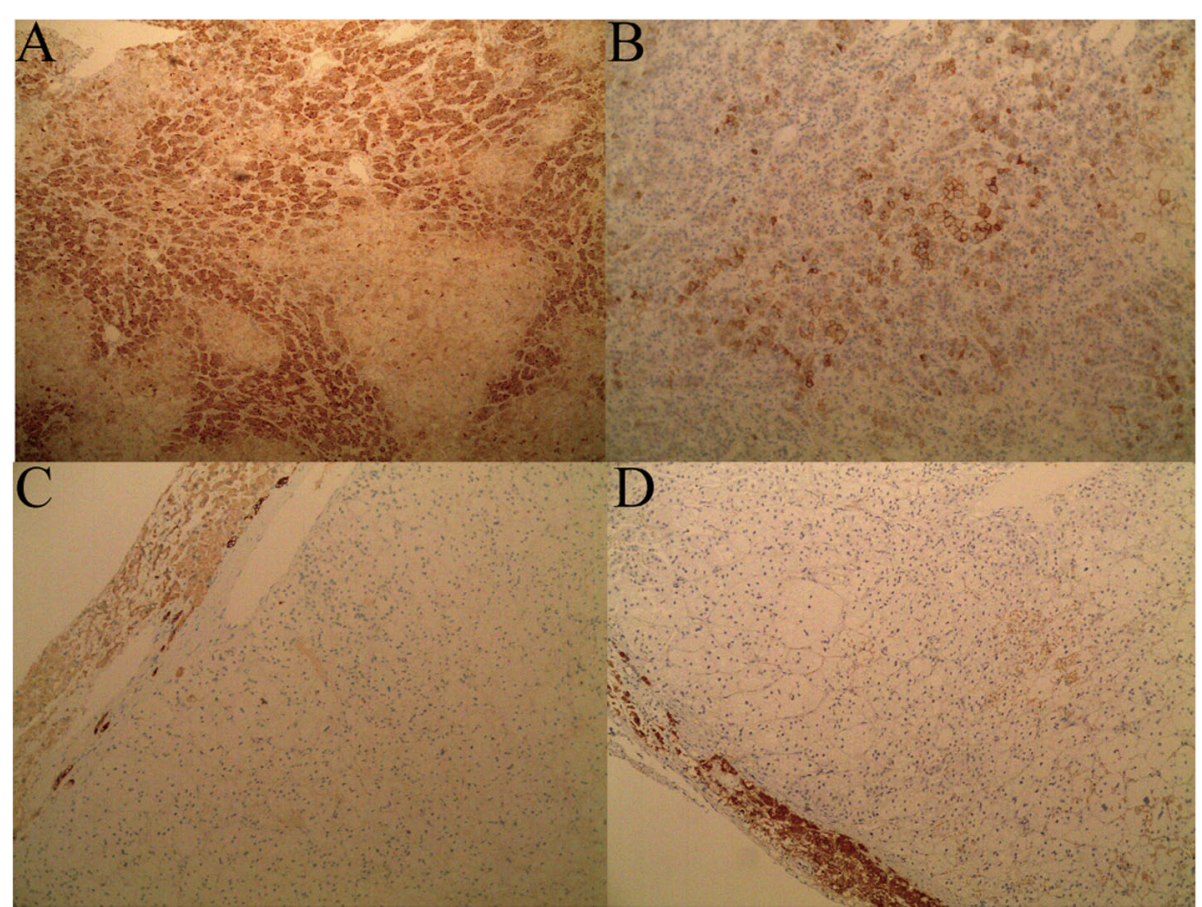

Fig. 6 a. Tumor cells were positive for inhibin-a; b. Tumor cells were positive for synaptophysin; c. Tumor cells were negative for CK; d. Tumor cells were negative for hepatocytes

Table 1 literature case reports summary

\begin{tabular}{|c|c|c|c|c|c|c|c|c|}
\hline $\begin{array}{l}\text { Year of } \\
\text { publication }\end{array}$ & Country & Year & Sex & $\begin{array}{l}\text { Diameter } \\
(\mathrm{cm})\end{array}$ & Chief complaint & Diagnosis & Therapy & Immunohistochemistry \\
\hline 2017 [2] & Korea & 56 & $\mathrm{~F}$ & 3.4 & "indigestion" & $\begin{array}{l}\text { Nonfunctional } \\
\text { adrenal adenoma }\end{array}$ & hepatectomy & $\begin{array}{l}\text { alpha-inhibin(+) } \\
\text { melan- } A(+) \\
\text { synaptophysin(+) }\end{array}$ \\
\hline 2017 [2] & Korea & 75 & M & 6.0 & "cholecystolithiasis" & $\begin{array}{l}\text { Nonfunctional } \\
\text { adrenal adenoma }\end{array}$ & hepatectomy & $\begin{array}{l}\text { alphainhibin }(+) \\
\text { melan- } A(+)\end{array}$ \\
\hline 2017 [2] & Korea & 64 & $\mathrm{~F}$ & 2.2 & "urinary tract infection" & $\begin{array}{l}\text { Nonfunctional } \\
\text { adrenal adenoma }\end{array}$ & hepatectomy & $\begin{array}{l}\text { alpha-inhibin(+) } \\
\text { melan-A(+) } \\
\text { synaptophysin(+) } \\
\text { glypican-3(+) }\end{array}$ \\
\hline 2016 [7] & Korea & 45 & $\mathrm{~F}$ & 1.4 & "Hypertension" & $\begin{array}{l}\text { Aldosterone } \\
\text { producing adenoma }\end{array}$ & Radiofrequency Ablation & not available \\
\hline $2009[8]$ & Korea & 45 & $\mathrm{~F}$ & 3.5 & "Leiomyoma of uterus" & $\begin{array}{l}\text { Nonfunctional } \\
\text { adrenal adenoma }\end{array}$ & hepatectomy & not available \\
\hline 2013 [9] & Japan & 60 & M & 3.0 & "Diabetes" & $\begin{array}{l}\text { Nonfunctional } \\
\text { adrenal adenoma }\end{array}$ & hepatectomy & not available \\
\hline 2007 [10] & Korea & 66 & $\mathrm{~F}$ & 1.5 & "rectal cancer" & $\begin{array}{l}\text { Nonfunctional } \\
\text { adrenal adenoma }\end{array}$ & hepatectomy & not available \\
\hline 2010 [11] & Korea & 45 & M & 2.7 & "heavy alcoholism" & $\begin{array}{l}\text { Nonfunctional } \\
\text { adrenal adenoma }\end{array}$ & tumorectomy & not available \\
\hline 2019 [12] & Korea & 59 & $\mathrm{~F}$ & 1.5 & "Hepatic nodules" & $\begin{array}{l}\text { Nonfunctional } \\
\text { adrenal adenoma }\end{array}$ & $\begin{array}{l}\text { laparoscopic surgical } \\
\text { resection }\end{array}$ & not available \\
\hline 2019 [12] & Korea & 75 & $\mathrm{~F}$ & 2.5 & $\begin{array}{l}\text { "rectal } \\
\text { nonmucinousadenocarcinoma" }\end{array}$ & $\begin{array}{l}\text { Nonfunctional } \\
\text { adrenal adenoma }\end{array}$ & $\begin{array}{l}\text { ultrasound-guided } \\
\text { core needle biopsy }\end{array}$ & $\begin{array}{l}\text { alpha-inhibin(+) } \\
\text { melan-A(+) }\end{array}$ \\
\hline
\end{tabular}


to establish standards for the diagnosis of hepatic adrenal adenoma. It should be pointed out that hepatic adrenal adenoma has malignant potential, it represent conditions requiring therapeutic intervention (e.g. larger than $4 \mathrm{~cm}$, the lesion enlarges by more than $20 \%$ after 6-12 months). We suggest performing hepatectomy through a laparoscopic access. However, laparoscopic surgery has higher requirements for the surgeons.

\section{Abbreviations}

CT: Computed tomography; MRI: Magnatic resonance imaging:

AHA: Adrenohepatic adhesion; AHF: Adrenohepatic fusion;

CEA: Carcinoembryonic antigen; AFP: Alpha fetoprotein; Hu: Hounsfield unit;

CA 125: Cancer antigen 125; CA 199: Cancer antigen 199; CK: Cytokeratin; HE: Hematoxylin and eosin; Hu: Hounsfield unit; RPR: Rapid plasma reagin test; DWI: Diffusion weighted imaging; ADC: Apparent diffusion coefficient

\section{Acknowledgments}

Not Applicable.

\section{Authors' contributions}

HBY and YDH were responsible for study design and writing. All authors read and approved the final manuscript.

\section{Funding}

Not applicable.

\section{Availability of data and materials}

All data produced and obtained is available within the manuscript.

\section{Ethics approval and consent to participate}

The study was approved on Wenzhou central Hospital ethical committee and informed consent was obtained from all individual participants included in the study.

\section{Consent for publication}

Written consent was obtained from patient authorizing to publish their individual data or any accompanied figures in this manuscript.

\section{Competing interests}

The authors declare that they have no competing interests.

Received: 19 January 2020 Accepted: 21 May 2020

Published online: 10 June 2020

\section{References}

1. Vestfrid MA. Ectopic adrenal cortex in neonatal liver. Histopathology. 1980; 4(6):669-72.

2. Park WY, Seo HI, Choi KU, Kim A, Kim YK, Lee SJ, Lee CH, Huh GY, Park DY. Three cases of adrenocortical tumors mistaken for hepatocellular carcinomas/diagnostic pitfalls and differential diagnosis. Ann Diagn Pathol. 2017;31:9-13.

3. Weller CV. Heterotopia of adrenal in liver and kidney. Am J Med Sci. 1925; 169(5):696-711.

4. Dolan MF, Janovski NA. Adreno-hepatic union. (Adrenal dystopia). Arch Pathol. 1968:86(1):22

5. Honoré LH, O'Hara KE. Combined Adrenorenal fusion and Adrenohepatic adhesion: a case report with review of the literature and discussion of pathogenesis. J Urol. 1976;115(3):323-5.

6. Honma K. Adreno-hepatic fusion. An autopsy study. Zentralblatt fur Pathologie. 1991;137(2):117-22.

7. Park JJ, Park BK, Kim JH, Jeong BC, Kim CK. Salvage computed tomographyguided transhepatic radiofrequency ablation for unresected aldosteronoma of adrenohepatic fusion after adrenalectomy. Int J Urol. 2016;23(1):102-4.

8. Park BK, Kim CK, Jung BC, Suh YL. Cortical adenoma in adrenohepatic fusion tissue: clue to making a correct diagnosis at preoperative computed tomography examination. Eur Urol. 2009;56(6):1082-5.
9. Machida Y, Takemoto A, Ban D, Yoshimoto T, Mihara M, Shibuya H. Adrenal cortical adenoma arising from an adrenohepatic union. Jpn J Radiol. 2013; 31(9):623-6.

10. Woo HS, Lee KH, Park SY, Han HS, Yoon CJ, Kim YH. Adrenal cortical adenoma in adrenohepatic fusion tissue: a mimic of malignant hepatic tumor at CT. AJR Am J Roentgenol. 2007;188(3):W246-8.

11. Yoon JH, Kim SH, Kim MA, Han JK, Choi BI. MDCT and Gd-EOB-DTPA enhanced MRI findings of adrenal adenoma arising from an ectopic adrenal gland within the liver: radiologic-pathologic correlation. Korean J Radiol. 2010;11(1):126-30

12. Cho YS, Kim JW, Seon HJ, Cho J-Y, Park J-H, Kim HJ, Choi YD, Hur YH. Intrahepatic adrenocortical adenoma arising from adrenohepatic fusion mimicking hepatic malignancy: two case reports. Medicine. 2019;98:e15901.

13. Park JJ, Park BK, Kim CK. Direct and indirect imaging features of adrenohepatic fusion. Abdom Radiol. 2016:41(2):377-83.

14. Israel GM, Korobkin M, Wang C, Hecht EN, Krinsky GA. Comparison of unenhanced $C T$ and chemical shift MRI in evaluating lipid-rich adrenal adenomas. AJR Am J Roentgenol. 2004;183(1):215-9.

15. Boland GW, Lee MJ, Gazelle GS, Halpern EF, McNicholas MM, Mueller PR Characterization of adrenal masses using unenhanced $\mathrm{CT}$ : an analysis of the CT literature. AJR Am J Roentgenol. 1998;171(1):201-4.

16. Kawasaki M, Yoshimura M, Sugimoto K, Takeuchi H, Saito K. Adrenocortical Scintigraphy with SPECT/CT for the diagnosis of hepatic adrenal rest. Clin Nucl Med. 2020:45:e192-4.

17. Howlett DC, Drinkwater K, Lawrence D, Barter S, Nicholson T. Findings of the UK national audit evaluating image-guided or image-assisted liver biopsy. Part I. procedural aspects, diagnostic adequacy, and accuracy. Radiology. 2012;265(3):819-31.

\section{Publisher's Note}

Springer Nature remains neutral with regard to jurisdictional claims in published maps and institutional affiliations.

Ready to submit your research? Choose BMC and benefit from

- fast, convenient online submission

- thorough peer review by experienced researchers in your field

- rapid publication on acceptance

- support for research data, including large and complex data types

- gold Open Access which fosters wider collaboration and increased citations

- maximum visibility for your research: over $100 \mathrm{M}$ website views per year

At BMC, research is always in progress.

Learn more biomedcentral.com/submissions 